\title{
Characterization of Microstructure Obtained by Boronitriding of an AISI H13 Steel
}

Marco Doñu Ruiz ${ }^{1}$, Noe Lopez Perrusquia ${ }^{2}$, Christopher René Torres San Miguel ${ }^{3}$, Norberto Mendoza Saucedo $^{1}$ and Victor Olmos Domínguez ${ }^{4}$

${ }^{1}$ Universidad Politécnica del Valle de México, Tultitlan, Distrito Federal, Mexico, ${ }^{2}$ Universidad Politecnica del Valle de México, Mexico, Distrito Federal, Mexico, ${ }^{3}$ Instituto Politécnico Nacional, Ciudad de Mexico, Distrito Federal, Mexico, ${ }^{4}$ Universidad Tecnológica de México, Estado de México, Distrito Federal, Mexico

Duplex treatment boronitriding on surface AISI H13 can change the chemical composition and microstructure of a relatively hard layer by diffusion in nitrogen and boron element, and improve the mechanical, physical, and chemical properties [1,2]. The evolution on microstructural characteristics on surface of AISI H13 steel have been studied by boronitriding as performed by dehydrated paste pack boriding (DP-PB) followed salt bath nitriding on surface AISI H13.

Specimens sizes of commercial AISI H13 steel with dimensions of a diameter of $12.7 \mathrm{~mm}$ and $10 \mathrm{~mm}$ thickness, then ground up to 1200 grit surface finish before duplex treatment. Boronitriding was performed in two processes; Firstly, samples H13 steel were packed in the dehydrated paste with a minimum of 10 $\mathrm{mm}$ of dehydrated paste coverage, sealed in a stainless steel container and place inside a resistance furnace without the use of a controlled atmosphere. The boriding treatment was carry out at $1173 \mathrm{~K}$ for $3 \mathrm{~h}$. Secondly, samples of $\mathrm{H} 13$ steel borided were nitride according to "tenifer bath nitriding" at $853 \mathrm{~K}$ for 1.5 $\mathrm{h}$. In each process, the cooling was at room temperature. In addition, the samples were sectioned by diamond saw and resin embedded, polished using standard metallographic techniques and then etched with $2 \%$ nital solution to reveal their cross-sectional microstructure. The microstructures were examined by scanning electron microscopy (JEOL JSM-6010LA) and phases on each conditions were identified by $\mathrm{X}$-ray diffraction (XRD) technique by $35 \mathrm{kV}$ and $25 \mathrm{~mA}$ with Cuk $\alpha$ radiation. The diffraction test was under taken by scanning from $20^{\circ}$ to $100^{\circ}$ for phase characterization on each condition.

Figure 1a shows a view cross-sectional SEM image on H13 steel borided, the morphology of the boride layers depicted is somewhere saw-toothed structure with the $\mathrm{FeB} / \mathrm{Fe}_{2} \mathrm{~B}$ and $\mathrm{Fe}_{2} \mathrm{~B} /$ substrate interface. A total layer thickness of $33.95 \pm 7.2 \mu \mathrm{m}$ with $14.6 \pm 5.2 \mu \mathrm{m}$ for $\mathrm{FeB}$ and $19.3 \pm 6.8 \mu \mathrm{m}$ for $\mathrm{Fe}_{2} \mathrm{~B}$. The crosssection of the boronitriding shows saw tooth features and the interface with the substrate that comprising three different regions and is shown in Figure 1b. i) mixture phases of nitride and boride, ii) diffusion zone and iii) the substrate iron. The boronitriding processes leads a mixture of different phases, such as $\varepsilon$-Fe ${ }_{3} \mathrm{~N}$, $\mathrm{FeB}$ and $\mathrm{Fe}_{2} \mathrm{~B}$ and DZ. A total mixture phases thickness of $18.23 \pm 12.8 \mu \mathrm{m}$ and DZ of $34.26 \pm 4.8 \mu \mathrm{m}$.

As a result of the first process in Figure 2 shows the XRD patterns for $\mathrm{H} 13$ steel borided, the presence of phases $\mathrm{FeB}$ and $\mathrm{Fe}_{2} \mathrm{~B}$ were confirmed, as well as the presence of $\mathrm{CrB}$ and $\mathrm{Cr} 2 \mathrm{~B}$ were identified, due to $\mathrm{Cr}$ content in the steel. In the second process, the nucleation of nitrides in columns of borides allows the formation of $\mathrm{Fe}_{3} \mathrm{~N}$, however, the constant saturation of nitrogen atoms reduces the $\mathrm{FeB}$ and $\mathrm{Fe}_{2} \mathrm{~B}$ layer, and the elimination of the $\mathrm{CrB}$ and $\mathrm{Cr}_{2} \mathrm{~B}$ phases, thus a hard layer with sawn morphology and diffusion zone was obtained by boronitriding process, resulted from XRD confirm the presence of phases type $\mathrm{Fe}_{3} \mathrm{~N}$, $\mathrm{FeB}$ and $\mathrm{Fe}_{2} \mathrm{~B}$ as show in Figure 2, also on the top surface was observed porosity. The porosity enhances the adhesion of sealants to the steel surface and improves their behavior in corrosion phenomena 

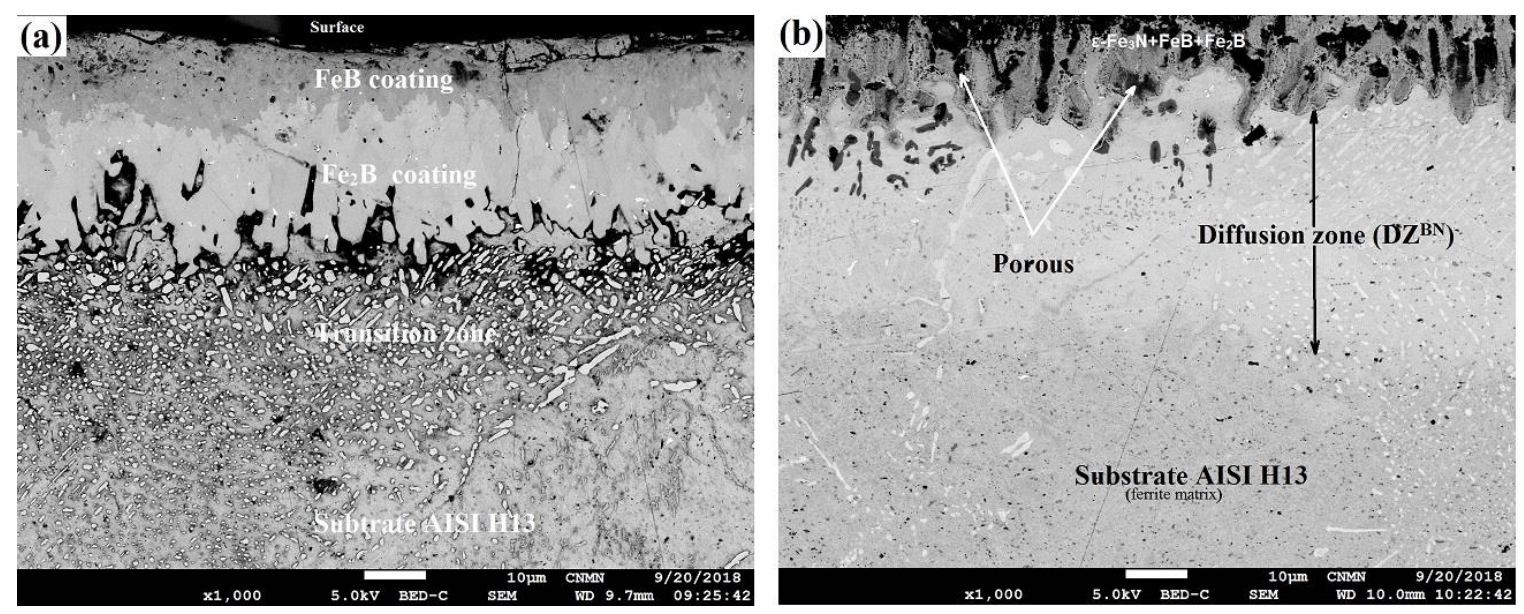

Figure 1. Cross-section micrograph on surface AISI H13 at condition of a) boride and b) boronitride

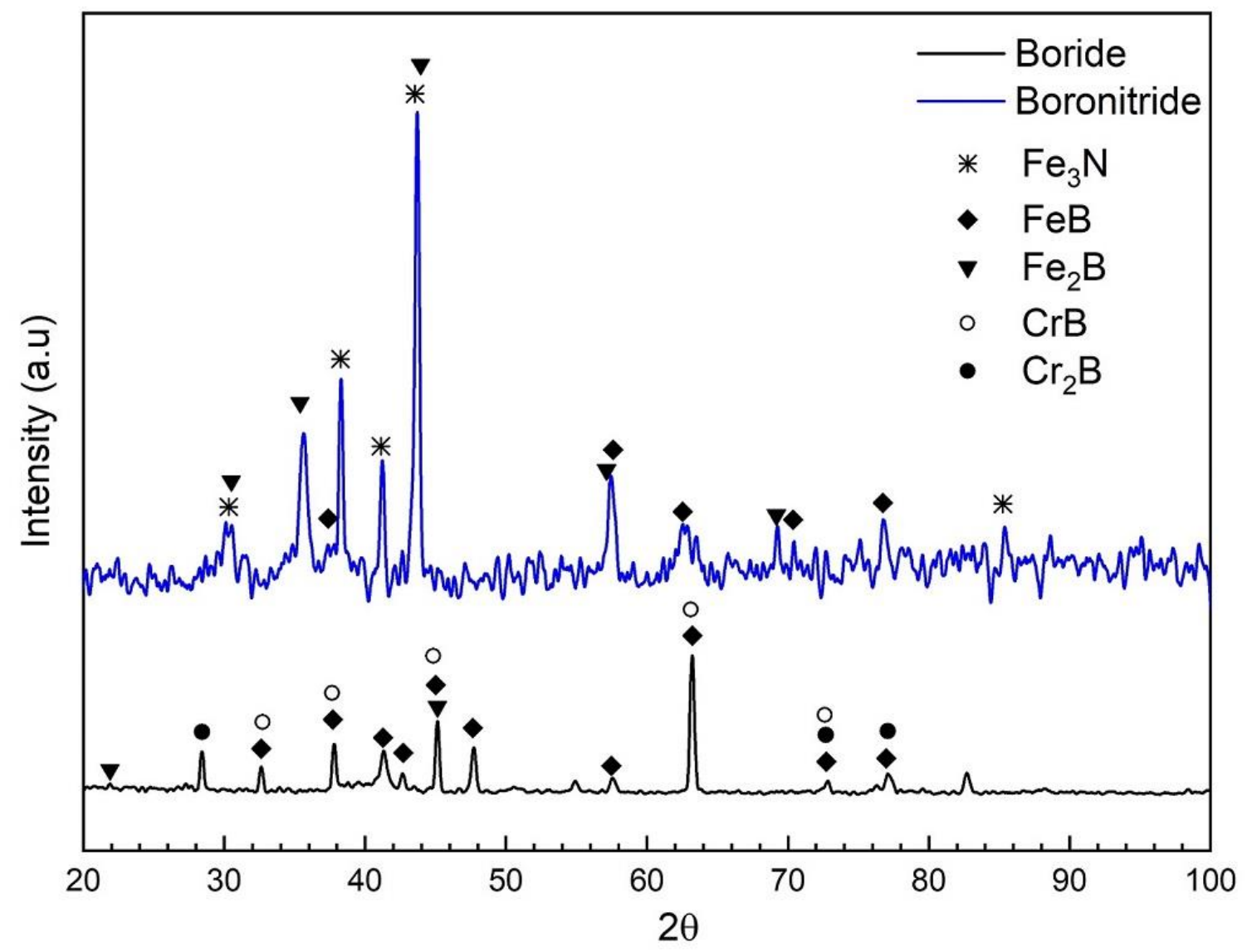

Figure 2. XRD pattern obtained on AISI H13 steel boride and boronitride References [1] J. Davis, Surface Hardening of Steels : Understanding the Basics., ASM Int. (2002). [2] E.J. Mittemeijer, Nitriding of binary and ternary iron-based alloys, in: Thermochem. Surf. Eng. Steels, Elsevier, 2015: pp. 313-340. 